\title{
Letters to the Editor
}

\begin{abstract}
The Editor does not hold himself responsible for opinions expressed by his correspondents. He cannot undertake to return, or to correspond with the writers of, rejected manuscripts intended for this or any other part of NATURE. No notice is taken of anonymous communications.

NOTES ON POINTS IN SOME OF THIS WEEK'S LETTERS APPEAR ON P. 591.

CORRESPONDENTS ARE INVITED TO ATTACH SIMILAR SUMMARIES TO THEIR COMMUNICATIONS.
\end{abstract}

\section{Newton's Prism in the British Museum}

A GLASS prism, said to have been the property of Isaac Newton, is on exhibition in the British Museum, Medieval Collections Room, Bay XVI. It was presented in 1927 by the Rev. H. T. Inman of Grantham, a collateral descendant of Newton, and resembles quite closely the prism seen in the hand of the statue of Newton in the ante-chapel of Trinity College, Cambridge. A question which naturally occurs to men of science who see this prism is whether it is one of those which Newton used in his famous experiments on the spectrum in 1666, described in his "Optical Lectures" of 1669, pp. 58 and 75, and reported also in Phil. Trans., 6, 3075 (1671).

Since Newton gave fairly explicit data on the refracting angle and index of refraction of the principal prism which he used on this notable occasion, the question of the association of the British Museum prism with Newton's early experiments might lend itself to a ready answer. Newton states, in the course of the aforementioned references, that the prism which he principally used had as its greatest angle $63^{\circ} 12^{\prime}$ and that its index of refraction for that portion of the spectrum "tending toward the middle of the green" was 17/11 (1.545).

This question had apparently not been explored until it was recently raised by $m e$ in a letter to Nature. The letter was referred to the British Museum authorities, whereupon Mr. N. J. Plenderleith, head of the Research Department, caused measurements to be made upon the prism which had suggested the inquiry. The report, from which I am permitted to quote, contains the following statements :

“. . . the characteristics differ markedly from those given by Newton in his paper (Phil. Trans., 1671, Vol. 6, p. 3077).

Prism Angle

ractive Index

(middle of the green)

Newton's Famous Prism

$63^{\circ} 12^{\prime}$ ( $\left.\max .\right)$

B.M. Prism

$1 \cdot 545$

$60^{\circ} \pm \frac{1}{2}^{\circ}$

$1.5933(5461)$

The specific gravity of the B.M. prism is $3 \cdot 36$. . . . The final conclusion is that the prism mentioned by Newton, although undoubtedly a flint glass, cannot possibly be identical with that now preserved by the British Museum."

The question still remains whether or not the British Museum prism is one of those which, though mentioned in Newton's writings, played a less prominent part in his early researches and for which his data are less explicit. It is, possibly, scarcely worth while to investigate this point.

LLOYd W. TAYLOR.

Department of Physics,

Oberlin College Ohio.

\section{Relationship between Post-Natal Coat Characters and Prenatal Follicle Density as Affected by Increase in Fœtal Size}

A series of New Zealand Romney foetuses have been studied with the view of showing that there is a correlation between post-natal coat characters and pre-natal follicle density as affected by increase in foetal size.

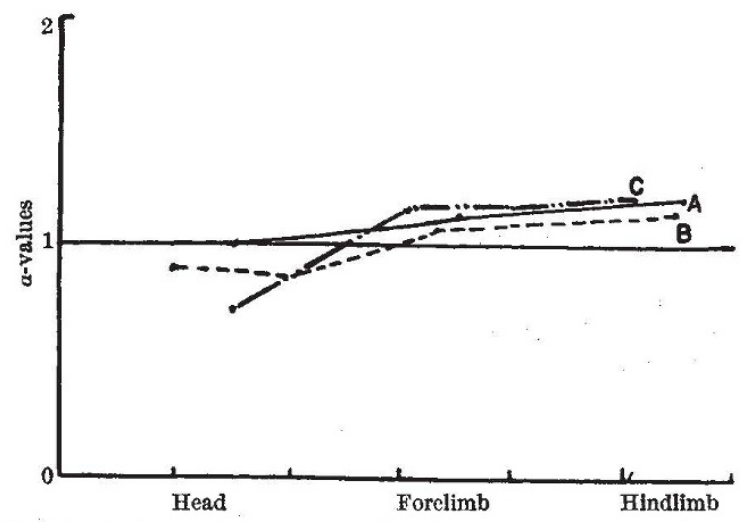

FIG. 1. Antero-posterior gradient in relative growth rate in length $(A)$, width $(B)$ and height $(C)$ at $46-86$ days.

It was found from the values of the equilibrium constant $^{1} \alpha$ for the different body regions that there exists after the 42nd day stage an antero-posterior gradient in the foetal relative growth rate for length, height and width. This gradient was slight up to the 80 -days stage but was marked from 80 days until 127 days (Figs. 1 and 2).

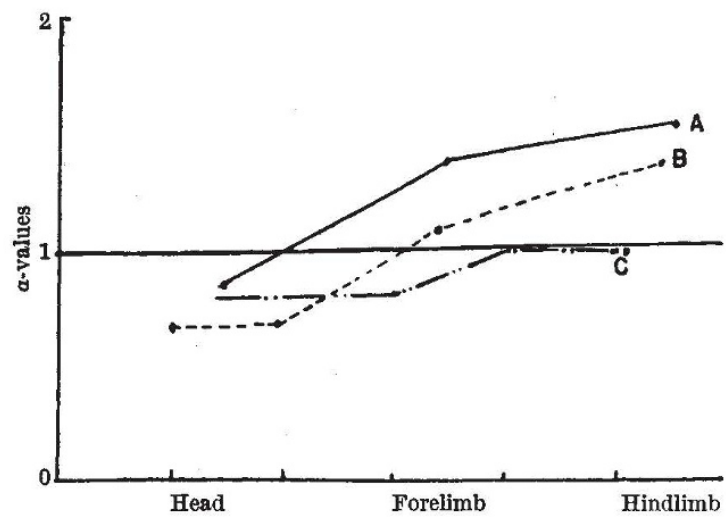

FrG. 2. Antero-posterior gradient in relative growth rate in length $(A)$, width $(B)$ and height $(C)$ at $86-122$ days.

This growth gradient was found to be comparable with the britch to poll fibre type_array gradient ${ }^{2}$ 